\title{
ChemComm
}

Check for updates

Cite this: Chem. Commun., 2019, 55, 9649

Received 20th March 2019, Accepted 16th July 2019

DOI: $10.1039 / c 9 c c 02215 e$ rsc.li/chemcomm

\section{Silica particles with a quercetin-R5 peptide conjugate are taken up into HT-29 cells and translocate into the nucleus $\uparrow$}

\author{
Giorgia Del Favero, (D) $\ddagger^{\mathrm{a}}$ Friedrich Bialas, $\ddagger^{\mathrm{b}}$ Stephanie Grabher, ${ }^{\mathrm{a}}$ Anja Wittig, ${ }^{\mathrm{a}}$ \\ Birgit Bräuer, ${ }^{b}$ Dagmar Gerthsen, ${ }^{c}$ Cécile Echalier, (DD ${ }^{d}$ Meder Kamalov, (D) ${ }^{b}$ \\ Doris Marko (D)*a and Christian F. W. Becker (DD*b
}

\begin{abstract}
Intracellular delivery of bioactive polyphenols is currently evaluated as a protective strategy for cells under pharmaceutical stress. To this end, the 20 mer R5 peptide from the marine diatom $C$. fusiformis was $\mathrm{N}$-terminally modified with a quercetin derivative. This polyphenolpeptide conjugate was used to generate homogeneous silica particles under biomimetic conditions that are efficiently taken up by eukaryotic cells without being cytotoxic. However, not only was accumulation in the cytoplasm of living cells observed via electron and fluorescence microscopy but also translocation into the nucleus. The latter was only seen when the quercetin-peptide conjugate was present within the silica particles and provides a novel targeting option for silica particles to nuclei.
\end{abstract}

Delivering biological cargo into cells is a complex process that is difficult to control and recent studies have taken advantage of mesoporous silica nanoparticles as a suitable delivery tool., Here we focused on a biomimetic strategy to generate silica particles that is based on the naturally occurring peptide R5 found in the marine diatom C. fusiformis. ${ }^{3}$ This 20 mer peptide generates, under biomimetic conditions, homogeneous spherical silica particles (SiPs). Alterations to the peptide structure and sequence, e.g. by adding posttranslational modifications or by shuffling the amino acid sequence, can lead to different particle morphologies. ${ }^{4,5}$ We have previously demonstrated that peptide and protein cargo can be efficiently encapsulated into the resulting silica particles without affecting their function.,

\footnotetext{
${ }^{a}$ Institute of Food Chemistry and Toxicology, Faculty of Chemistry, University of Vienna, Waehringer Strasse 38, 1090 Vienna, Austria.

E-mail: doris.marko@univie.ac.at

${ }^{b}$ Institute of Biological Chemistry, Faculty of Chemistry, University of Vienna, Waehringer Strasse 38, 1090 Vienna, Austria.E-mail: christian.becker@unvie.ac.at Laboratory for Electron Microscopy, Karlsruhe Institute of Technology (KIT), Engesserstrasse 7, 76131 Karlsruhe, Germany

d Institut des Biomolécules Max Mousseron (IBMM), UMR5247 CNRS, ENSCM, Université de Montpellier, 15 Avenue Charmes Flahault, 34093 Montpellier Cedex 05, France

$\dagger$ Electronic supplementary information (ESI) available: Experimental procedures, supplementary figures and tables. See DOI: 10.1039/c9cc02215e

\$ Authors contributed equally.
}

Together with our current findings that hydrophobic N-terminal modifications of the R5 sequence support self-assembly of the peptide prior to silica precipitation, ${ }^{8}$ this has led us to generate a covalent conjugate of a bioactive polyphenol, namely quercetin, with the R5 peptide (Fig. 1A-C). Quercetin is a common dietary polyphenol, also widely used as food supplement. ${ }^{9}$ Even if wellknown and characterized, thanks to its strong biological activity, quercetin is of continuously rising scientific interest. ${ }^{10-12}$

For introducing a carboxylic acid linker into quercetin without affecting its function we chose to address the 7-hydroxy group. This was achieved by first completely acetylating quercetin with an excess of acetic anhydride in pyridine at $70{ }^{\circ} \mathrm{C}$. It was then regioselectively deprotected with imidazole and thiophenol in NMP as described by Kim et al. to give the 7-Omonodeacetylated product. ${ }^{13}$ Subsequently, the carboxylic acid linker was introduced by addition of ethyl iodoacetate. The intermediate 3 was then deprotected using hydrochloric acid in refluxing acetone as described by Mattarei et al. (11\% yield over 4 steps, Fig. 1A). ${ }^{14}$ Coupling to the 20 mer R5 peptide was performed on resin prior to cleavage and purification (Fig. 1B). The cleaved conjugate was then purified by RP-HPLC (Fig. 1C). The resulting quercetin-R5 conjugate was dissolved at $1 \mathrm{mg} \mathrm{ml}^{-1}$ concentration in phosphate buffer at $\mathrm{pH} 7$ and freshly generated silicic acid was added to give highly homogeneous silica particles with a peptide loading of $>95 \%$. Particles were separated by centrifugation, washed and imaged by scanning electron microscopy (SEM, Fig. 1D). The obtained particles were spherical with a diameter of $\sim 400 \mathrm{~nm}$. Release of the conjugate from the silica particles in $50 \mathrm{mM}$ potassium phosphate buffer at neutral $\mathrm{pH}$ and pH 4 was followed by UV-VIS spectroscopy, based on the absorbance of quercetin at $375 \mathrm{~nm}$. Here, a pH-dependent release could be observed. At $\mathrm{pH} 4,45 \%$ of the quercetin-R5 conjugate was found in the supernatant after $5 \mathrm{~h}$, whereas at neutral $\mathrm{pH}$ only $10 \%$ were released after $5 \mathrm{~h}$ and no further increase in released conjugate was observed (Fig. 1F).

Therefore, quercetin-R5 containing SiPs were incubated in aqueous buffer at $\mathrm{pH} 7.4$ before incubation with cells for $5 \mathrm{~h}$ to remove loosely associated quercetin-R5. To investigate the 
A

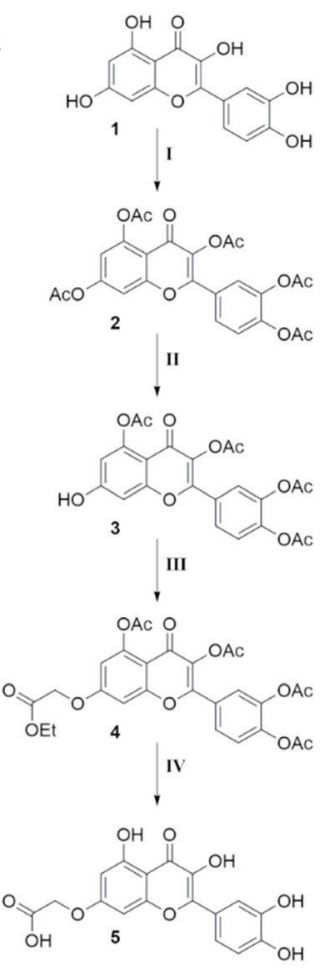

B
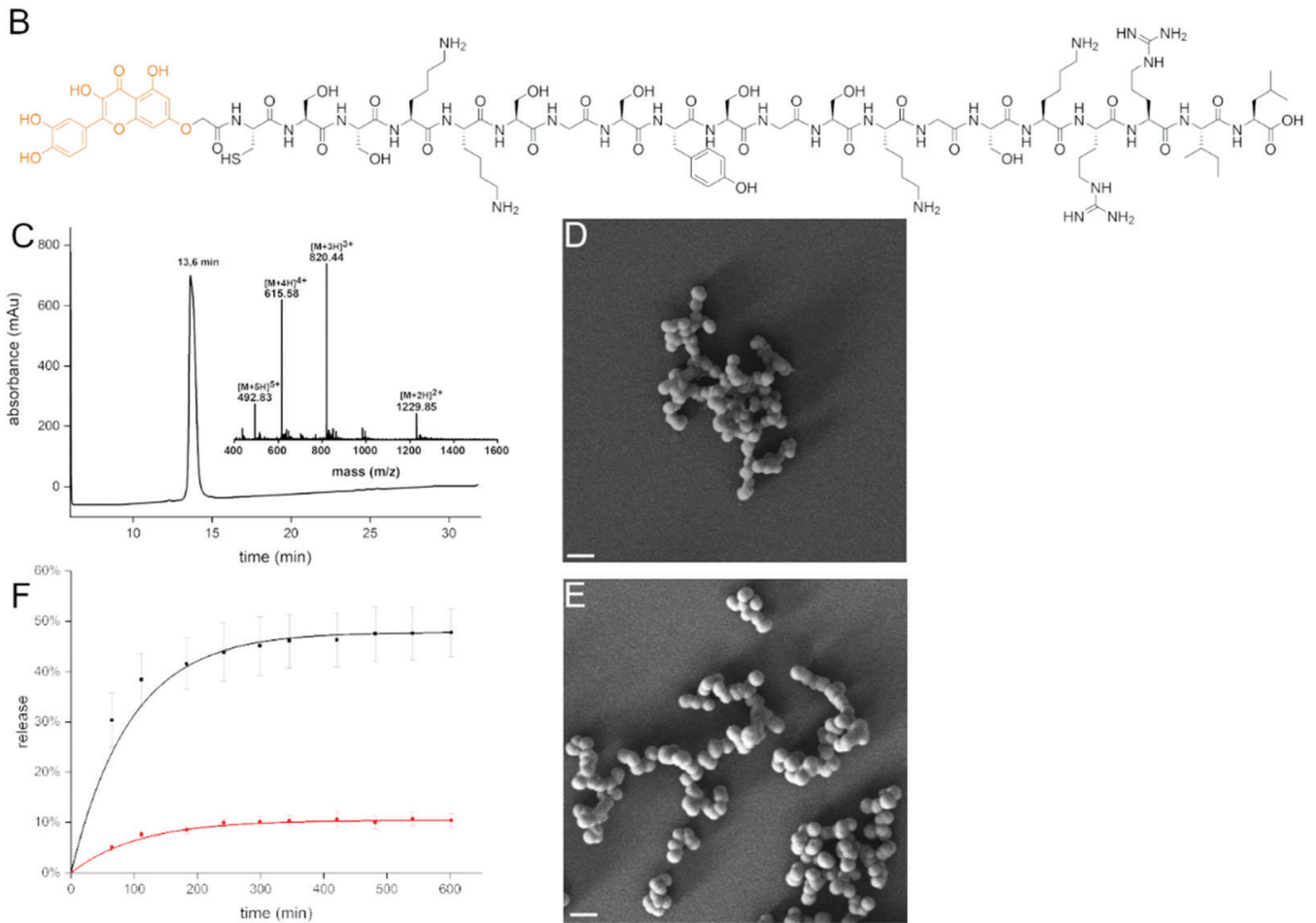

D
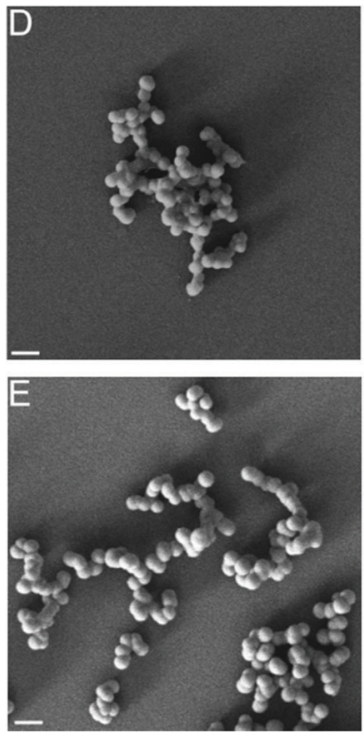

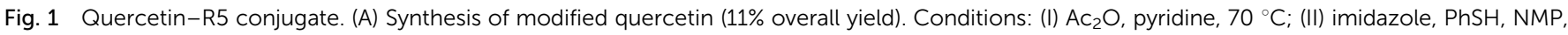

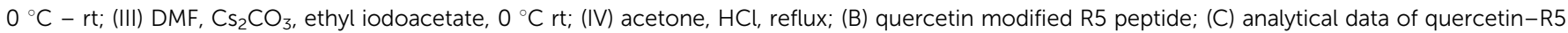

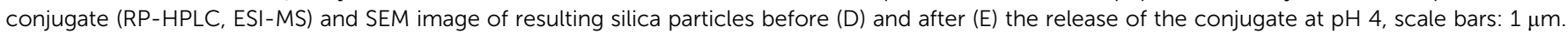
(F) Release of quercetin-R5 conjugate from silica particles followed by absorbance of the supernatant at $375 \mathrm{~nm}$ at $\mathrm{pH} 7$ (red) and at $\mathrm{pH} 4$ (black).

morphology of the particles after release of a large fraction of the conjugate, a sample of the particles was incubated for $4.5 \mathrm{~h}$ in $50 \mathrm{mM}$ phosphate buffer at $\mathrm{pH}$ 4. The particles were then imaged by SEM showing that they retained their spherical shape (Fig. 1E). The supernatant of the particles after $10 \mathrm{~h}$ incubation at $\mathrm{pH} 4$ was also analysed by LC-MS and clearly indicated that the released conjugate was fully intact (Fig. S1, ESI $\dagger$ ).

To test uptake of R5-based silica particles, human colon adenocarcinoma HT-29 cells were cultivated and incubated with R5-silica particles not containing quercetin. High-angle annular dark-field scanning transmission electron microscopy (HAADFSTEM) experiments on ultrathin cell sections were performed to analyse intact cells and locate SiPs. Biomimetic SiPs show strong bright contrast in HAADF-STEM images and appear to accumulate at the cellular membrane already after $1 \mathrm{~h}$ of incubation with HT-29 cells (Fig. 2A). Accordingly, after $24 \mathrm{~h}$ of incubation massive accumulation of SiPs in the intracellular compartment but not in the nucleus was observed (Fig. 2B). Once we verified that biomimetic R5-SiPs can enter the intracellular compartment, a fluorescent variant was used in combination with live cell imaging to follow the kinetic of uptake at the cellular level. The fluorescein-labeled silane triethoxysilyl fluorescein was incorporated into SiPs at a ratio of 1 to 20 to the R5 peptide. ${ }^{15}$ Similarly, a progressive uptake was observed that led to accumulation of the fluorescent SiPs in the cytoplasm of HT-29 cells after $3 \mathrm{~h}$ (Fig. 2C and D). Cytotoxicity measurement revealed no toxicity of biomimetic SiPs in HT-29 cells (Fig. S2, ESI $\dagger$ ). ${ }^{16}$
After demonstrating uptake of R5-SiPs into HT-29 cells without detectable effects on cell viability, we moved on to quercetin-R5-based SiPs. These SiPs behaved similarly to the R5- and fluorescein-R5-SiPs described above. Interestingly, we noticed that the intrinsic fluorescence of the quercetin-R5 peptide, even when incorporated in SiPs, was sufficient for live cell imaging (Fig. S3, ESI $\dagger$ ). Concentration-dependent quercetin fluorescence was measured in HT-29 cells to determine the optimal concentration for live cell imaging (Fig. S4, ESI $\dagger$ ). Based on these results, in combination with cytotoxicity data for R5 SiP, uptake experiments were performed at concentrations of $70 \mu \mathrm{M}$ quercetin or quercetin-R5 SiP, respectively.

The intrinsic fluorescence of the quercetin-R5 conjugate allowed us to study uptake without any additional labelling, which also excludes undesired effects of labels on the uptake and targeting mechanisms. Here, uptake into HT-29 cells was followed by live cell imaging and proved that already after $3 \mathrm{~h}$ a major fraction of quercetin-R5 SiPs was found in cells (Fig. 3A-D). However, uptake of quercetin-R5 SiPs starts immediately after the application but it takes at least $90 \mathrm{~min}$ to reach the nucleus/ peri-nuclear region (Fig. S5, ESI $\dagger$ ). In order to verify if the uptake of quercetin-R5-SiPs was an active process or a consequence of an alteration of the permeability of the cell membrane, respective live cell imaging experiments were performed (Fig. S6, ESI $\dagger$ ). Confocal live imaging microscopy allowed us to follow the uptake of quercetin-R5 SiPs and subsequent interaction with the plasma membrane (Fig. S6, ESI $\dagger$ ). Uptake of the quercetin-R5 SiPs 

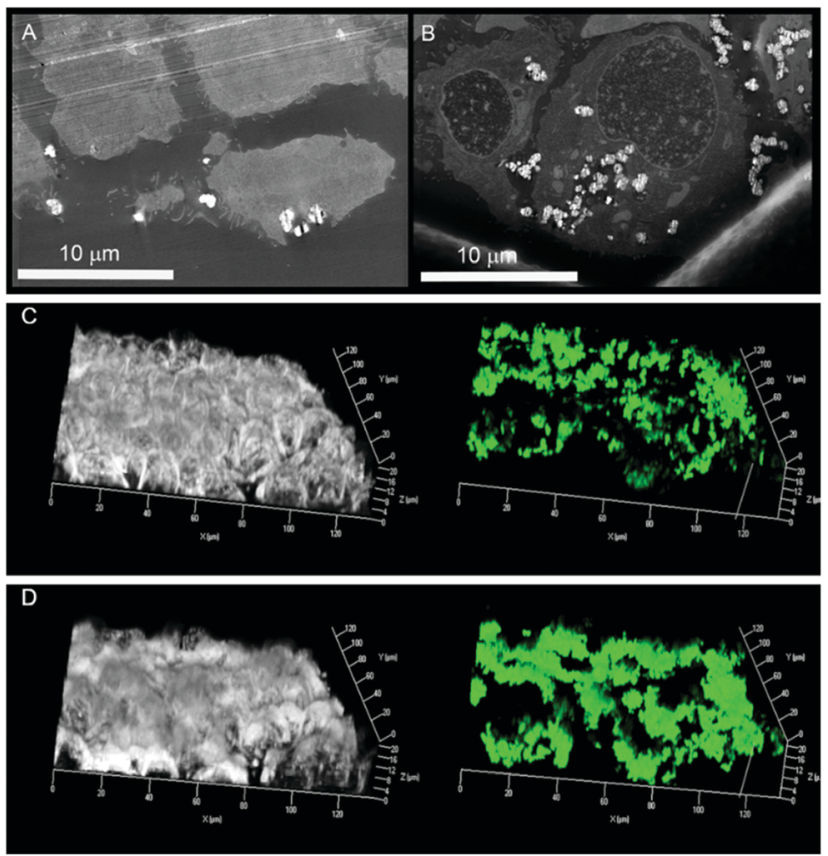

Fig. 2 High-angle annular dark-field scanning transmission electron microscopy (HAADF-STEM) images of ultrathin sections of HT-29 cells after $1 \mathrm{~h} \mathrm{(A)}$ and $24 \mathrm{~h}(\mathrm{~B})$ incubation with R5-peptide containing SiPs. SiPs show strong bright contrast in HAADF-STEM images. Uptake was also visualized by live cell fluorescence measurements with fluorescein-labeled R5 SiPs at $t=0(C)$ and $t=180 \mathrm{~min}$. (D) The bright lines in the upper part of (A) are artifacts from ultramicrotomy used for thin-section preparation.

occurred through active engulfment of the particles followed by recovery of the membrane surface to its original integrity, thus suggesting the SiPs uptake to be an active, energy-dependent process and not a secondary effect of the particles sustained by a loss of membrane integrity. These findings are supported by uptake experiments at $4{ }^{\circ} \mathrm{C}$ and in the presence of wortmannin as an inhibitor of phagocytosis/micropinocytosis ${ }^{17}$ and after treatment with methyl- $\beta$-cyclodextrin $(\mathrm{m} \beta \mathrm{CD})$ to deplete cholesterol and induce alterations of membrane organization and fluidity (Fig. S7, ESI $\dagger$ ). ${ }^{18}$ The uptake of quercetin-R5 SiPs was severely reduced at $4{ }^{\circ} \mathrm{C}$ and SiPs are mainly found on the cell surface after $3 \mathrm{~h}$. However, as the wortmannin and $\mathrm{m} \beta \mathrm{CD}$ treatment did not lead to significant changes in uptake of quercetin-R5 SiPs, we can currently only exclude the related uptake mechanisms of phagocytosis/micropinocytosis and caveolin-mediated endocytosis for HT-29 cells. Moreover, the quercetin-modified SiPs accumulated inside the nucleus (Fig. $3 \mathrm{E}$ and $\mathrm{F}$ and cross sections of the cell surface/central section), a behaviour not observed for any other SiPs investigated here and rarely for silica (nano-) particles tested in other studies. ${ }^{19,20}$

To control if this targeting effect was accompanied by a biological effect, comet assay (single cell gel electrophoresis) experiments were performed with the quercetin-R5 SiPs in comparison to the corresponding concentration of quercetin $(70 \mu \mathrm{M})$, quercetin-R5 and R5 SiPs. Interestingly, binding of quercetin to SiPs abolished the genotoxic effect of the unconjugated compound (Fig. S8, ESI $\dagger$ ).
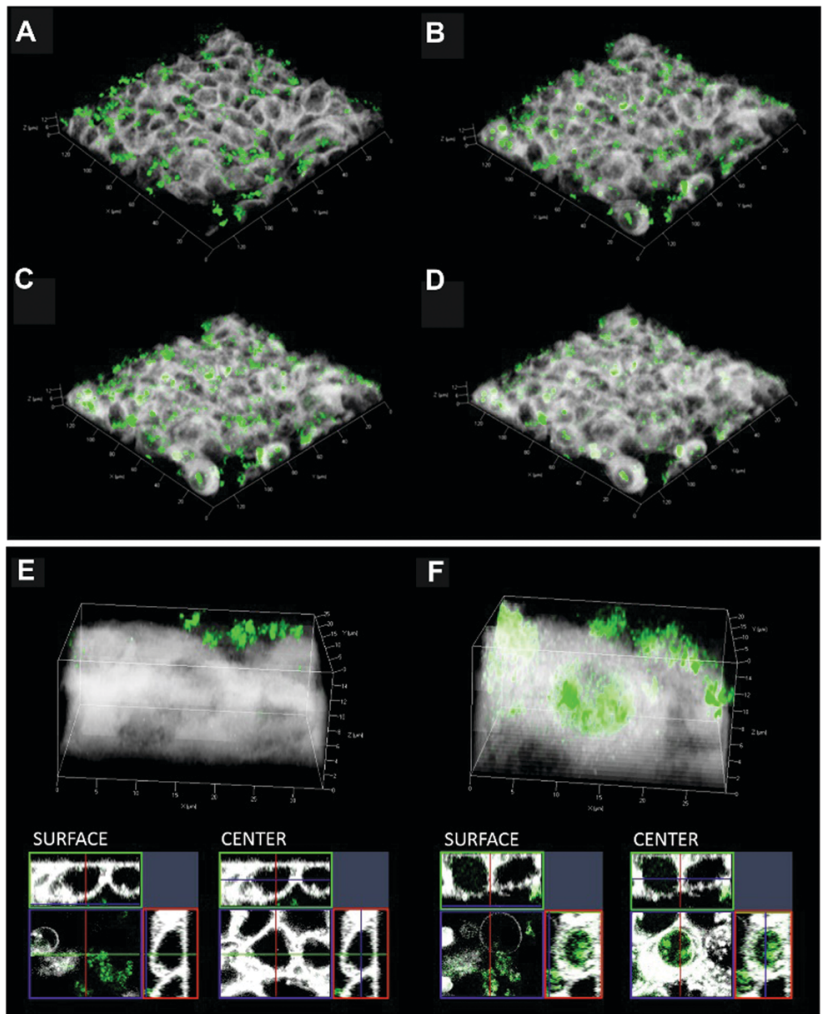

Fig. 3 Analysis of quercetin-R5 SiP (green) uptake into HT-29 cells by live cell fluorescence imaging (cell membrane is depicted in white). Pictures are showing the time course of uptake (A) $1 \mathrm{~min}$; (B) $60 \mathrm{~min}$. (C) $120 \mathrm{~min}$. (D) $180 \mathrm{~min}$. Appearance of the 3D reconstruction and of the cross sections SURFACE level and central section of HT-29 cells (CENTER) 1 min after the application of SiPs (E) and at the end of the incubation (180 min (F)).

Overall, we describe a new strategy to target biomimetic silica particles to the nucleus of eukaryotic cells without any detectable effects on cell viability. Covalent conjugation of the bioactive food constituent quercetin to a similarly safe silaffin-based peptide that is used to generate biomimetic silica, provides an almost ideal cellular shuttle. To attach cargo to this shuttle the cysteine residue offers itself as an attachment point that could be used to release cargo via redox-mediated processes on its way through the cytoplasm or via more stable linkages within the nucleus.

We gratefully acknowledge help from Carolin Lechner, Helge Gehrke, Georg Aichinger, Svenja Hankele and Holger Blank with sample preparation and data collection. This project has received funding from the European Union's Horizon 2020 research and innovation programme under the Marie Sklodowska-Curie grant agreement no. 675007 .

\section{Conflicts of interest}

There are no conflicts to declare.

\section{Notes and references}

1 J. Lee, D. G. Jo, D. Park, H. Y. Chung and M. P. Mattson, Pharmacol. Rev., 2014, 66, 815-868. 
2 A. Watermann and J. Brieger, Nanomaterials, 2017, 7, 189-205.

3 R. D. Nils Kröger and M. Sumper, Science, 1999, 286, 1129-1132.

4 C. C. Lechner and C. F. W. Becker, Chem. Sci., 2012, 3, 3500.

5 C. C. Lechner and C. F. Becker, J. Pept. Sci., 2014, 20, 152-158.

6 C. C. Lechner and C. F. Becker, Bioorg. Med. Chem., 2013, 21, 3533-3541.

7 C. C. Lechner and C. F. Becker, Biomater. Sci., 2015, 3, 288-297.

8 M. Kamalov, A. Hajradini, C. Rentenberger and C. F. W. Becker, Mater. Lett., 2018, 212, 114-117.

9 C. Chalet, J. Rubbens, J. Tack, G. S. Duchateau and P. Augustijns, J. Pharm. Pharmacol., 2018, 70, 1002-1008.

10 Q. Wu, P. A. Kroon, H. Shao, P. W. Needs and X. Yang, J. Agric. Food Chem., 2018, 66, 7181-7189.

11 Y. Jin, Z.-l. Huang, L. Li, Y. Yang, C.-h. Wang, Z.-t. Wang and L.-l. Ji, Acta Pharmacol. Sin., 2018, 40, 75-85.

12 F. Aghapour, A. A. Moghadamnia, A. Nicolini, S. N. M. Kani, L. Barari, P. Morakabati, L. Rezazadeh and S. Kazemi, Biochem. Biophys. Res. Commun., 2018, 500, 860-865.
13 M. K. Kim, H. Choo and Y. Chong, J. Med. Chem., 2014, 57, 7216-7233.

14 A. Mattarei, L. Biasutto, F. Rastrelli, S. Garbisa, E. Marotta, M. Zoratti and C. Paradisi, Molecules, 2010, 15, 4722-4736.

15 J. Ciccione, T. Jia, J.-L. Coll, K. Parra, M. Amblard, S. Jebors, J. Martinez, A. Mehdi and G. Subra, Chem. Mater., 2016, 28, 885-889.

16 A. Wittig, H. Gehrke, G. Del Favero, E. M. Fritz, M. Al-Rawi, S. Diabate, C. Weiss, H. Sami, M. Ogris and D. Marko, Nanomaterials, 2017, 7, 18.

17 H. Herd, N. Daum, A. T. Jones, H. Huwer, H. Ghandehari and C. M. Lehr, ACS Nano, 2013, 7, 1961-1973.

18 X. Zhang, J. Hurng, D. L. Rateri, A. Daugherty, G. W. SchmidSchonbein and H. Y. Shin, Am. J. Physiol.: Cell Physiol., 2011, 301, C451-C460.

19 A. S.-S. K. AbouAitah, A. A. Farghali, J. Wojnarowicz, A. Stefanek, S. Gierlotka, A. Opalinska, A. K. Allayeh, T. Ciach and W. Lojkowski, Oncotarget, 2018, 9, 26466-26490.

20 L. Xiong, X. Du, F. Kleitz and S. Z. Qiao, Small, 2015, 11, 5919-5926. 